revista do ieb n 45 p. 11-20 set 2007

\title{
Pernambuco e o trópico
}

Manoel Correia de Oliveira Andrade ${ }^{1}$

Resumo

0 estudo geográfico do território pernambucano, abordando as condições naturais como um todo, os domínios físicos - a estrutura geológica, o relevo, o clima, a hidrografia e a flora -, é o tema deste artigo. A segunda parte detalha aspectos econômicos e sociais relativos a uma das áreas do Estado: o município de Ipojuca, situado na microrregião geográfica de Suape, integrante da Mesorregião Metropolitana de Recife.

\section{Palavras-chave}

geografia física, geografia humana, região, Pernambuco, Ipojuca.

1 Professor Emérito da Universidade Federal de Pernambuco, responsável pela Cátedra Gilberto Freyre, membro da Academia Pernambucana de Letras.

Falecido em 22 de junho de 2007. 
revista do ieb n 45 p. 11-20 set 2007

\section{Pernambuco and the tropics}

Manoel Correia de Oliveira Andrade

Abstract

The geographical study of the state of Pernambuco, encompassing the natural conditions as a whole, the physical aspects - geological structure, relief, climate, hydrography, flora -, is the subject of this article. The second part details some economic and social aspects of one area in the state: the city of Ipojuca.

\section{Keywords}

physical geography, human geography, region, Pernambuco, Ipojuca. 


\section{Pernambuco e o trópico}

0 Estado de Pernambuco encontra-se inteiramente inserido na região intertropical, entre as latitudes de $7^{\circ} 15^{\prime}$ ao norte e de $9^{\circ} 27^{\prime}$ ao sul do Equador.

Se compararmos com as terras a igual latitude, situadas na África e na América do Sul, observaremos que há um grande contraste climático entre esses dois continentes; enquanto aqui dominam as caatingas próprias das regiões semi-áridas, na outra margem do Atlântico dominam as florestas equatoriais drenadas pelo rio Congo ou Zaire, com vegetação semelhante à amazônica.

0 território pernambucano ${ }^{2}$ está localizado, em sua maior porção, sobre rochas ígneas e metamórficas, muito antigas, pré-cambrianas, e em porções bem menos extensas, formadas por rochas sedimentares mais jovens, que datam do Terciário e do Quaternário. Estas se encontram, sobretudo, no litoral, onde estão os sedimentos quaternários e as famosas deposições da série Barreiras, bem mais extensas ao norte que ao sul do Recife, e em largas porções da chapada do Araripe e do vale do Moxotó, sobre o pediplano cristalino sertanejo. Encontramos, ainda, formas residuais de pequena extensão, mas de altitude expressiva, como a Serra Negra situada nos municípios de Floresta, Inajá e Tacaratu, cobertas por florestas consideradas como do tipo Amazônico e afloramentos vulcânicos em Ipojuca e no Cabo de Santo Agostinho, próximos ao litoral do Estado.

A unidade morfológica que domina o relevo pernambucano, o maciço da Borborema, estende-se no sentido Norte-Sul, desde o Rio Grande do Norte até Alagoas, atravessando os estados da Paraiba e de Pernambuco por cerca de $250 \mathrm{~km}$, enquanto no sentido Leste-0este ele é ora mais largo ora mais estreito, oscilando entre os 100 e os $150 \mathrm{~km}$. Apesar de tratar-se de relevo pré-cambriano, distingue-se bastante do relevo de igual idade, do Sudeste e do Sul do Brasil, por achar-se mais gasto

2 Cf. ANDRADE, Manoel Correia de. A Serra de Ororobá. Contribuição ao estudo dos níveis de erosão do Planalto da Borborema. Recife, 1955. p.7-9. Tese apresentada à Assembléia Geral da Associação dos Geógrafos Brasileiros em Garanhuns (PE).Mimeog.; ANDRADE, Manoel Correia de. A "Ria" do Rio Formoso da Costa Sul de Pernambuco: comunicação a ser apresentada ao XVIII Congresso Internacional de Geografia... no Rio de Janeiro em agosto de 1956. Recife: Universidade do Recife, Faculdade de Filosofia de Pernambuco, 1956; ANDRADE, Manoel Correia de. A terra e o homem no Nordeste: contribuição ao estudo da questão agrária no Nordeste. 7. ed. rev. e aum. São Paulo: Cortez, 2005. p. 41. GUERRA, A. T.; GUERRA, A. J. T. Dicionário geológico-geomorfológico. Rio de Janeiro: Bertrand Brasil, 1997; AB' SABER, Aziz. O Planalto da Borborema, na Paraíba. Boletim Paulista de Geografia, São Paulo, n. 13, p. 54-5, 1953. 
pela erosão, por não haver sido rejuvenescido e por localizarse a maior distância do oceano. Suas altitudes que raramente atingem os $1000 \mathrm{~m}$ são bem mais modestas que as assinaladas na Serra do Mar e da Mantiqueira onde, em alguns pontos, aproximam-se dos $3000 \mathrm{~m}$. É também menos imponente porque suas escarpas não caem diretamente sobre o mar, formando costões elevados, já que estão bastante distantes do mesmo - cerca de 40 a $60 \mathrm{~km}$-, sendo a superfície intermediária ocupada por terraços litorâneos um pouco mais elevados que o nível do mar, por tabuleiros e por colinas mamelonares.

A dissecação do velho planalto, feita em função de níveis de erosão que variaram através das eras e períodos geológicos, assim como os movimentos tectônicos ocorridos, possivelmente no Eoceno, são responsáveis por falhas que tiveram grande influência na rede de drenagem e no modelado hoje dominante na Borborema, quer quanto à posição das superfícies de aplainamento, quer quanto aos níveis de erosão encontrados, tanto sobre o planalto quanto na sua encosta oriental. Observamos uma sucessão de níveis, como o de $1000 \mathrm{~m}$, na serra de Ororobá, em Pesqueira e no monte Magano, em Garanhuns, de 700 a $750 \mathrm{~m}$ nas cristas que separam os vales que dissecam a Borborema e, ainda, de 450 e de $350 \mathrm{~m}$, nas encostas do maciço - Surubim e Gravatá, por exemplo. Estes níveis, escalonando em degraus a escarpa do maciço, favoreceram, no passado, a sua ocupação e povoamento e diminuíram as dificuldades de construção das estradas que o galgam.

Porções mais altas são encontradas ao sul no planalto de Garanhuns e no centro e norte, nas cristas que servem de divisores de águas entre os vales do Capibaribe, do Ipojuca e do Una, os três rios que dissecam o planalto em sentido Oeste-Leste.

A porção do território pernambucano localizada a leste da Borborema apresenta características diversas das do sul e do norte do paralelo do Recife. Assim, observa-se a dominância de colinas arredondadas, de forma mamelonar, separadas umas das outras por largos vales fluviais, por córregos e grotas, na porção sul, enquanto na porção norte estas formações morfológicas são substituídas por formações barreiras, aplainadas em níveis que oscilam entre os 40 e os 130 metros. Nesta porção norte, de clima menos úmido, os interflúvios são formados por superfícies planas que quando talham terrenos cristalinos são chamados de chãs, e quando talham terrenos sedimentares são chamados de tabuleiros. Os vales fluviais próximos à foz dos rios são muito largos, formados por várzeas pleistocênicas e pliocênicas, ricas em turfa e solos de massapé.

Ao oeste da Borborema, a região sertaneja apresenta-se mais elevada ao norte - Chapada do Araripe - e ao oeste - Serra 
de Dois Irmãos - com altitudes que se aproximam dos 700m. Ao sul, no cotovelo que o rio São Francisco faz ao separar o território pernambucano do baiano, encontramos altitudes que se aproximam dos $400 \mathrm{~m}$ em Petrolina, descem para os $300 \mathrm{~m}$ em Cabrobó, para cair aos 219m nas proximidades da foz do rio Moxotó, na fronteira alagoana, apresentando um traçado que lembra um anfiteatro no qual as porções mais altas estariam ao norte, ao oeste e ao leste e a porção mais baixa ao sul. No meio deste, elevam-se serras e chapadas cujas altitudes oscilam desde os 700 até os $1000 \mathrm{~m}$ - Serra Negra e do Periquito -, testemunhando a existência, no passado, de uma superfície aplainada bem mais elevada do que a hoje existente.

Localizado na faixa intertropical, a menos de $10^{\circ} \mathrm{de}$ latitude Sul, Pernambuco possui um clima que apresenta sempre temperaturas elevadas. A temperatura média do mês mais frio é sempre superior a $18^{\circ} \mathrm{C}$, característica dos climas tropicais. Apenas em áreas pouco extensas e elevadas é que encontramos temperaturas mais baixas, amenizadas pela altitude. A distância do litoral também influencia o clima, pois, enquanto na faixa litorânea as amplitudes térmicas diurnas são pequenas, no Agreste e, sobretudo, no Sertão, áreas mais distantes do litoral, elas se elevam, às vezes, a mais de $5^{\circ} \mathrm{C}$. A amplitude térmica anual, porém, é muito baixa em todo o Estado.

As diferenciações climáticas no território pernambucano resultam, sobretudo, da quantidade e da distribuição das chuvas, uma vez que as variações térmicas são insignificantes.

Podemos admitir que a região da Mata e a porção meridional do Agreste possuem clima As' da classificação de Köppen, ou seja, o clima tropical chuvoso com precipitações de outonoinverno. Encontramos, porém, nesta área, duas pequenas ilhas climáticas representadas, na Mata Úmida, ao sul, pela região em torno de Barreiros onde domina o clima Am, tropical de monções, e pela área em torno da cidade de Garanhuns onde domina o clima Csa, ou seja, sub-tropical com chuvas de inverno e temperaturas tanto no inverno como no verão amenizadas pela altitude. Na porção norte ocidental do Agreste e em todo o Sertão pernambucano domina o clima BSH, semi-árido estépico quente, com chuvas de verão-outono em algumas áreas e de outono-inverno em outras bem menos extensas. Na pequena porção sertaneja limítrofe com o Ceará, observamos a dominância do clima Aw', ou seja, tropical chuvoso com chuvas dominantemente de primavera-verão.

A rede hidrográfica do Estado tem como centro dispersor de águas o maciço da Borborema, que separa as águas que correm para o leste, para a vertente Atlântica, das que correm para o sudoeste, para a vertente do rio São Francisco. Na porção oriental 
da Borborema, correndo para o leste e aproveitando quase sempre vales em forma de graben, estão os três principais rios do Estado que deságuam no Oceano Atlântico - o Capibaribe, o Ipojuca e o Una. Estes rios, com algumas centenas de quilômetros de comprimento, têm o seu alto e médio cursos no Agreste e apresentam regime temporário, enquanto no baixo curso, na região da Mata, eles são perenes. Nas proximidades da foz, devido à transgressão marinha pleistocênica, eles têm os vales afogados pela penetração da água do mar, formando autênticas rias. Além desses rios, existem os que nascem na porção mais oriental do maciço da Borborema e têm quase todo o seu curso na região da Mata, como o Capibaribe-Mirim, o Tracunhaém - os dois formadores do Goiana -, o Botafogo, o Jaboatão, o Pirapama, o Sirinhaém e o Formoso. Outros, menores, formam-se na própria região da Mata e se lançam no Atlântico, como o Beberibe - ou se tornam afluentes dos rios principais - o Siriji.

Apesar de terem extensão, largura e volume d'água modestos, nos alto e médio cursos, eles se apresentam bastante largos nas proximidades da foz, devido à influência das marés, e correm em amplas várzeas lamacentas de solos turfosos onde crescem manguezais.

0 rio São Francisco banha o território pernambucano em um longo percurso no qual separa este Estado do da Bahia; a presença de cachoeiras, corredeiras e quedas d'água torna a navegação aí mínima, só sendo possível ser feita em pequenos trechos e por pequenas embarcações. Na verdade, Petrolina, com seu porto, é o ponto terminal na navegação no médio São Francisco, enquanto o baixo São Francisco só é navegado a jusante de Piranhas, onde ele separa os estados de Alagoas e Sergipe. Para o São Francisco correm, em Pernambuco, alguns de seus afluentes pela margem esquerda, a exemplo do Ipanema, Moxotó, Pajeú, Garças e Brígida. Estes afluentes possuem regime torrencial, correndo apenas na estação das chuvas.

O São Francisco é aproveitado pelo homem, através da realização de obras hidráulicas e da utilização de suas águas para produção de energia e para irrigação. Ele tem sido alvo de programas, como o da transposição de suas águas para irrigação de terras no Ceará, na Paraíba e no Rio Grande do Norte e para o chamado Canal do Sertão, em Pernambuco, o que levaria água, captada a montante de Sobradinho, para o Sertão pernambucano. 0 problema da transposição das águas tem sido objeto de grandes discussões sobre a conveniência ou não de fazê-la.

No que diz respeito à vegetação, ela está sempre dependente da influência dos fatores clima, relevo e solo. Deste modo, a leste, nas proximidades da costa, nas praias de areia, dominam as associações típicas das restingas; naquelas por- 
ções em que, devido à baixa altitude e à proximidade dos rios, existe diariamente uma alternância de águas doces e salgadas, dominam as formações de mangues. Nas áreas sedimentares que se encontram nas proximidades do litoral, mas que se alteiam, às vezes, até mais de $100 \mathrm{~m}$, e que são observados na porção norte da região da Mata, desenvolve-se uma associação vegetal rica em cajueiros, mangabeiras, cajueiros brabos, batiputás etc. fisionomicamente semelhante à formação dos cerrados da região Central do país e que são conhecidos como tabuleiros.

A ação antrópica ao longo dos anos vem sendo muito intensa nesses ecossistemas. Os mangues, apesar de protegidos, desde 1993, pelo Decreto Federal n 750, vêm sofrendo fortes impactos negativos face à atuação do homem. A carcinicultura, o desmatamento para produção de lenha, a especulação imobiliária, esgotos industriais e domésticos, lixo são causas que têm contribuído para a degradação desse ecossistema. 0 mesmo vem acontecendo com as áreas de restingas; no litoral sul de Pernambuco merece destaque a restinga de Arinquindá, no município de Tamandaré, incluída na Área de Proteção Ambiental de Guadalupe como um dos remanescentes desse ecossistema no Estado.

Maior extensão, porém, tinha a área ocupada pela Mata Atlântica, que se estendia pelas várzeas dos rios, colinas e chãs da região da Mata e subia a encosta da Borborema, dominando as áreas mais altas e mais expostas aos ventos de Sudeste. No Sertão, sobre serras mais elevadas, como a Negra e a da Baixa Verde, havia também uma densa floresta tropical. Essa Mata Atlântica, porém, foi quase completamente destruída em quatro séculos de colonização. A floresta situada nas áreas mais acessíveis começou a ser destruída no século XVI, ao iniciar-se o ciclo da cana-de-açúcar, a fim de desocupar as terras que seriam ocupadas por esta cultura e também para fornecer lenha às fornalhas dos engenhos, que só a partir do século XIX passaram a usar o bagaço da cana como combustível. No século XIX e na primeira metade do século XX, porém, se os engenhos deixaram de consumir lenha em suas fornalhas, eles foram substituídos, como agentes de destruição de nossas matas, pelas padarias, pelos fogões domésticos e pelas locomotivas das estradas de ferro. Nos brejos do Agreste, a expansão dos cafezais acelerou também a destruição das florestas, que havia sido iniciada com a cultura de lavouras de subsistência e de cana-de-açúcar para a produção de rapadura.

Na porção sub-úmida e semi-árida do Agreste e na maior parte da região sertaneja, domina a caatinga, chamada de mata branca, rala, dos indígenas. Não é uma vegetação uniforme, apresentando-se ora mais ora menos densa, de maior ou de menor porte, ora mais ora menos rica em cactáceas. Walter Egler, 
em seu trabalho "Contribuição ao estudo da Caatinga Pernambucana”, na Revista Brasileira de Geografia, distingue no Sertão pernambucano vários tipos de caatinga: a seca e agrupada, a seca e esparsa, a arbustiva densa, a das serras e do chapadão do Moxotó ${ }^{3}$. De um modo geral, a caatinga é formada por vegetais adaptados ao clima semi-árido; daí para se defenderem da evaporação, ora são desprovidos de folhas, como as cactáceas, ora se despem das mesmas durante o estio, enquanto outros se defendem da seca criando sobre as folhas uma camada impermeabilizante de cera ou, então, desenvolvem raízes tuberosas que lhes permitem armazenar, na curta estação chuvosa, a água necessária a sua alimentação durante o estio.

Nas áreas mais povoadas, a caatinga vem perdendo o porte e a densidade, face às queimadas sucessivas feitas com o intuito de formar pastagens.

Sobre a chapada do Araripe, em solos silicosos, encontramos também uma vegetação do tipo cerrado, rica em cajueiros, pequizeiros e mangabeiras. Contudo, grande parte dessa vegetação está sendo destruída ou degradada devido à expansão da cultura da mandioca, à utilização da chapada para o pastoreio durante a estação seca e à produção de lenha para alimentar os grandes fornos que transformam as rochas de gipsita em pó de gesso.

\section{Visita a Ipojuca}

Município situado na microrregião geográfica de Suape, integrante da Mesorregião Metropolitana de Recife, Ipojuca oferece grandes oportunidades de desenvolvimento econômico e de atração aos visitantes da metrópole pernambucana. Ele apresenta do ponto de vista fisiográfico uma grande diversificação; localizado nas proximidades do mar, tem uma larga faixa de praia de areia e uma bela foz, a do rio Ipojuca, onde se situa a enseada de Suape; enseada porto, visitada, em 1500, por Vicente Pinzon, antes do descobrimento do Brasil, onde ele aportou e explorou o Cabo de Santo Agostinho, já no município deste nome. 0 porto foi utilizado, durante os primeiros anos da guerra holandesa, por Matias de Albuquerque, depois que Recife e Olinda caíram em poder dos batavos.

3 EGLER, Walter Albert. Contribuição ao Estudo da Caatinga Pernambucana.

Revista Brasileira de Geografia, Rio de Janeiro, ano 13, n. 4, p. 577-591, 1951. 
Reunido com outros rios, como o Aribim, e por braços de maré, ele forma um delta interior, fechado por uma cadeia de recifes, com numerosas ilhas tradicionalmente habitadas por pescadores e apanhadores de caranguejos e siris. Ao Oeste, encontramos uma extensa planície dominada ora por solos silicosos de restingas, ora por solos argilosos de massapé. Nas restingas os colonizadores portugueses cultivaram, ainda no período Colonial, os coqueirais trazidos do Oriente, enquanto no massapé cultivaram a cana de açúcar.

Ainda hoje as duas paisagens se sucedem e permitem o desenvolvimento, ao Leste, de praias de veraneio, como a de Porto de Galinhas e a de Muro Alto. Nos solos de massapé, onde existiam, nos períodos Colonial e Imperial, numerosos engenhos bangüês, hoje encontramos duas importantes usinas, a Salgado e a Ipojuca. No litoral observa-se a existência de aldeias povoadas por pescadores, praias luxuosas de veraneio com hotéis e pousadas de alto nível, vilas e povoações. Entre as vilas salienta-se a de Nossa Senhora do Ó, que por algum tempo foi sede do município e hoje compete como centro urbano com a mesma. Nesta faixa situa-se o engenho Canoas, reminiscência dos tempos dos bangüês e que ainda hoje fabrica rapadura e melaço para a venda no mercado recifense. Uma visita ao mesmo é interessante para que se tenha uma idéia da economia açucareira da época dos bangüês. Para o interior, existe uma grande produção de fruteiras que tem o seu mercado sempre em crescimento, com a demanda de turistas que, no verão, procuram as praias. É também área de atração para esportes náuticos e de visita às piscinas naturais formadas por recifes. Os passeios de barcos podem ser estendidos até a ilha de Santo Aleixo, na foz do Sirinhaém, que foi palco, no século XVI, de lutas entre franceses e portugueses pelo controle do comércio do pau-brasil.

A riqueza do município se completa com grandes canaviais e monumentos históricos, como o convento de Santo Antonio de Ipojuca, na sede municipal e a partir da criação do município observa-se, como salienta o historiador José Geraldo de Souza Leão, uma disputa constante entre as duas candidatas à sede municipal, a vila de Nossa Senhora do Ó, formada pela população litorânea e dominada por pequenos produtores que se dedicam à exploração de pequenas propriedades, ao artesanato, à pesca, e outra, dominada pelos grandes proprietários de terra e plantadores de cana que movimentavam os seus engenhos utilizando o braço escravo e em seguida o dos moradores de "condição". Daí haver se consubstanciado a vida política do município entre duas classes sociais, a chamada aristocracia açucareira, que deu nobres e titulares ao Império, e a população humilde e trabalhadora que desejava e constituía uma sociedade 
mais democrática. A luta social que ocorreu em Pernambuco estruturou-se também em bases econômicas, concentrando um grupo na atual cidade de Ipojuca e outro na vila de Nossa Senhora do Ó. Luta que provocou numerosas vezes a transferência da sede municipal de uma para outra vila, hoje se transforma, devido ao crescimento da imigração e de uma população oriunda do Recife, de outros pontos do Brasil e até do exterior, sem compromissos com os dois principais grupos.

Um outro fato ocorreu, já no século XX, com o crescimento da povoação, hoje vila de Camela, onde foi criada uma grande indústria de cachaça, fazendo com que ela se tornasse, por algum tempo, uma terceira competidora das duas vilas tradicionais. 0 encerramento da produção de cachaça, porém, fez com que a área meridional de Ipojuca passasse a participar da porção canavieira, dando uma maior unidade ao município, onde se observam, em alguns trechos, jazidas de caolin, exploradas por indústrias de cerâmica.

A nosso ver, porém, o destino de Ipojuca como centro muito próximo ao Recife - faz parte da Região Metropolitana - é o de se transformar em área de forte industrialização, o que em parte já vem ocorrendo, face à presença, em seu território e no do município vizinho, do Cabo de Santo Agostinho, do Complexo Industrial Portuário de Suape. Ipojuca se destaca, também, por ser área de veraneio, em virtude do parque turístico praieiro que agrupa. 